\title{
Chromium ions in alkali lead borotellurite glasses - An EPR and optical study
}

\author{
R. P. Sreekanth Chakradhar ${ }^{* *, 1}$, J. Lakshmana Rao, ${ }^{*}$, G. Sivaramaiah $^{2}$, and N. O. Gopal ${ }^{2}$ \\ ${ }^{1}$ Department of Physics, Indian Institute of Science, Bangalore, 560 012, India \\ 2 Department of Physics, Sri Venkateswara University, Tirupati, 517 502, India
}

Received 9 January 2005, revised 13 July 2005, accepted 27 July 2005

Published online 6 September 2005

PACS 61.43.Fs, 76.30.Fc, 78.40.Pg

Chromium ions doped $90 \mathrm{Na}_{2} \mathrm{~B}_{4} \mathrm{O}_{7}+(9-x) \mathrm{PbO}+1 \mathrm{TeO}_{2}$ and $90 \mathrm{~K}_{2} \mathrm{~B}_{4} \mathrm{O}_{7}+(9-x) \mathrm{PbO}+1 \mathrm{TeO}_{2}(x=3,4$, 5, 6, 7 and $8 \mathrm{~mol} \%$ ) glasses have been studied by using Electron Paramagnetic Resonance (EPR) and optical absorption techniques. The EPR spectra exhibit a broad resonance signal at $g=4.65$ and a narrow resonance signal at $g=1.97$. The resonance at $g=4.65$ can be attributed to isolated $\mathrm{Cr}^{3+}$ ions in rhombic symmetry subjected to strong crystal field effects and the resonance at $g=1.97$ is due to $\mathrm{Cr}^{5+}$ ions. The EPR spectra have also been studied at different temperatures $(153-393 \mathrm{~K})$. The number of spins $(N)$ participating in the resonance is measured as a function of temperature and the activation energy is calculated. The exchange coupling constant $J$ between chromium ions is calculated. The optical absorption spectrum exhibits bands characteristic of $\mathrm{Cr}^{3+}$ ions in an octahedral symmetry. The optical band gap $\left(E_{\text {opt }}\right)$ and Urbach energies $(\Delta E)$ have been calculated for all the glass samples and it is observed that $E_{\text {opt }}$ decreases and $\Delta E$ increases with increase of chromium content. This has been explained as due to the creation of additional localized states with chromium doping, which overlap and extend in the mobility gap of the glass matrix.

() 2005 WILEY-VCH Verlag GmbH \& Co. KGaA, Weinheim

\section{Introduction}

Recently glasses based on $\mathrm{TeO}_{2}$ and heavy metal oxides have stirred up significant interest in the field of new glassy materials [1-5]. These materials have shown high density, high refractive index and for their excellent transmission in the visible and near infrared (IR) region, optical non-linearity effect and due to their potential applications such as IR domes, modulators, memories, optical switching, and laser windows, they become promising materials for manifold possible applications. It is known that $\mathrm{TeO}_{2}$ in combination with heavy metal oxides, like $\mathrm{PbO}$, forms stable glasses. Further, these glasses are considered as very good materials for hosting lasing ions like chromium since these provide a low phonon energy environment to minimize non-radiative losses.

Moreover, in applications ranging from new optical material research to optoelectronic and integrated optical devices, there has been increasing interest in glasses due to their lower production costs with respect to single crystals. One of the most investigated transition metal impurity ions is chromium and the large number of review articles and papers testifies to the high level of interest in this field [6-12], even in connection with the development of lasers. Currently, the basic features of chromium in a large number of crystalline matrices are so well established that this ion is extensively used as a probe for studying the structure and the local symmetry of new and exotic materials.

\footnotetext{
* Corresponding author: e-mail: jrao46@yahoo.co.in

** e-mail: chakra72@physics.iisc.ernet.in
} 
Table 1 Composition (mol\%) of glasses studied in the present work.

\begin{tabular}{|c|c|c|c|c|c|c|}
\hline glass system & glass code & $\begin{array}{l}\mathrm{Na}_{2} \mathrm{~B}_{4} \mathrm{O}_{7} \\
10 \mathrm{H}_{2} \mathrm{O}\end{array}$ & $\begin{array}{l}\mathrm{K}_{2} \mathrm{~B}_{4} \mathrm{O}_{7} \\
5 \mathrm{H}_{2} \mathrm{O}\end{array}$ & $\mathrm{PbO}$ & $\mathrm{TeO}_{2}$ & $\begin{array}{l}\text { ammonium } \\
\text { dichromate }\end{array}$ \\
\hline $\begin{array}{l}\text { Sodium lead } \\
\text { borotellurite glass }\end{array}$ & $\mathrm{NaPbBTe}$ & 90 & - & 9 & 1 & - \\
\hline $\begin{array}{l}\text { Sodium lead } \\
\text { borotellurite glass } \\
8\left(\mathrm{NH}_{4}\right)_{2} \mathrm{Cr}_{2} \mathrm{O}_{7}\end{array}$ & NaPbBTe: $8 \mathrm{Cr}$ & 90 & - & 1 & 1 & 8 \\
\hline $\begin{array}{l}\text { Potassium lead } \\
\text { borotellurite glass }\end{array}$ & $\mathrm{KPbBTe}$ & - & 90 & 9 & 1 & - \\
\hline $\begin{array}{l}\text { Potassium lead } \\
\text { borotellurite glass } \\
3\left(\mathrm{NH}_{4}\right)_{2} \mathrm{Cr}_{2} \mathrm{O}_{7}\end{array}$ & KPbBTe:3Cr & - & 90 & 6 & 1 & 3 \\
\hline $\begin{array}{l}\text { Potassium lead } \\
\text { borotellurite glass } \\
4\left(\mathrm{NH}_{4}\right)_{2} \mathrm{Cr}_{2} \mathrm{O}_{7}\end{array}$ & $\mathrm{KPbBTe}: 4 \mathrm{Cr}$ & - & 90 & 5 & 1 & 4 \\
\hline $\begin{array}{l}\text { Potassium lead } \\
\text { borotellurite glass } \\
5\left(\mathrm{NH}_{4}\right)_{2} \mathrm{Cr}_{2} \mathrm{O}_{7}\end{array}$ & KPbBTe:5Cr & - & 90 & 4 & 1 & 5 \\
\hline $\begin{array}{l}\text { Potassium lead } \\
\text { borotellurite glass } \\
6\left(\mathrm{NH}_{4}\right)_{2} \mathrm{Cr}_{2} \mathrm{O}_{7}\end{array}$ & KPbBTe:6Cr & - & 90 & 3 & 1 & 6 \\
\hline $\begin{array}{l}\text { Potassium lead } \\
\text { borotellurite glass } \\
7\left(\mathrm{NH}_{4}\right)_{2} \mathrm{Cr}_{2} \mathrm{O}_{7}\end{array}$ & KPbBTe:7Cr & - & 90 & 2 & 1 & 7 \\
\hline $\begin{array}{l}\text { Potassium lead } \\
\text { borotellurite glass } \\
8\left(\mathrm{NH}_{4}\right)_{2} \mathrm{Cr}_{2} \mathrm{O}_{7}\end{array}$ & KPbBTe:8Cr & - & 90 & 1 & 1 & 8 \\
\hline
\end{tabular}

No EPR and optical absorption studies of chromium ions in alkali lead borotellurite glasses have been reported so far. In the present study, the authors report the structural investigation of chromium ions in the alkali lead borotellurite glass matrices performed by means of Electron Paramagnetic Resonance (EPR) and optical absorption techniques. The authors are also interested to find the variation of EPR line intensity with temperature, which allows one to calculate the exchange-interaction energy $J$ between chromium pairs. The results obtained from these studies are discussed in detail.

\section{Experimental}

All the batch materials $\left(\mathrm{Na}_{2} \mathrm{~B}_{4} \mathrm{O}_{7} \cdot 10 \mathrm{H}_{2} \mathrm{O}, \mathrm{K}_{2} \mathrm{~B}_{4} \mathrm{O}_{7} \cdot 5 \mathrm{H}_{2} \mathrm{O}, \mathrm{PbO}\right.$ and $\left.\mathrm{TeO}_{2}\right)$ used in the present study were of Analar grade quality. Chromium was added to the batches as ammonium dichromate $\left[\left(\mathrm{NH}_{4}\right)_{2} \cdot \mathrm{Cr}_{2} \mathrm{O}_{7}\right]$. The glass samples were prepared by the melt quenching method with the compositions given in Table 1 . All the chemicals were weighed accurately using an electrical balance, ground to fine powder and mixed thoroughly. The batches were melted for 2.5 hours in porcelain crucibles at $1126 \mathrm{~K}$. The melts were then poured on a polished brass plate and pressed quickly with the other brass plate. The glasses thus obtained were transparent. The glasses were then annealed at $423 \mathrm{~K}$. Care was taken to obtain the glasses of uniform thickness for recording optical absorption spectra. Good quality glasses obtained after polishing were used for optical measurements.

The EPR spectra were recorded at room as well as at different temperatures $(153-393 \mathrm{~K})$ on an EPR spectrometer (JEOL FE1X) operating at the X-band microwave frequency $(9.205 \mathrm{GHz})$ with a modulation frequency of $100 \mathrm{kHz}$. The magnetic field was scanned from 0 to $500 \mathrm{mT}$ with a scan speed of 
$62.5 \mathrm{mT} / \mathrm{min}$. A coarsely powdered glass specimen of $100 \mathrm{mg}$ was taken in a quartz tube for EPR measurements. The EPR spectrum of the $\mathrm{CuSO}_{4} \cdot 5 \mathrm{H}_{2} \mathrm{O}$ powdered material was also recorded as a reference for calculating the absolute number of spins in various glasses.

The EPR spectra of $8 \mathrm{~mol} \%$ of $\mathrm{Cr}_{2} \mathrm{O}_{7}$ doped potassium lead borotellurite (KPbBTe: $8 \mathrm{Cr}$ ) glass sample is recorded at different temperatures $(153-393 \mathrm{~K})$ using a variable temperature controller (JES UCT $2 \mathrm{AX})$. A temperature stability of $\pm 1 \mathrm{~K}$ was easily obtained by waiting approximately half an hour at the set temperature before recording a spectrum at each temperature.

The optical absorption spectra of all the glass samples doped with chromium ions were recorded at room temperature on a JASCO (V-570) UV-VIS-NIR spectrophotometer in the wavelength region 200-900 nm. Glass samples of thickness nearly $1 \mathrm{~mm}$ were used for optical measurements.

\section{Results and discussion}

\subsection{Electron paramagnetic resonance studies}

No EPR signals were detected in the spectra of undoped glasses indicating that the starting materials used in the present work were free from transition metal impurities (or paramagnetic defects). When various mol\% of $\mathrm{Cr}_{2} \mathrm{O}_{7}$ were added to the glasses, all glass samples under investigation exhibit resonance signals characteristic of chromium in other glass systems [4-26]. Figure 1 shows the EPR spectra of $8 \mathrm{~mol} \% \mathrm{Cr}_{2} \mathrm{O}_{7}$ in sodium lead borotellurite and potassium lead borotellurite glass samples at room temperature. The EPR spectra of all the glasses exhibit a sharp resonance line centered at $g=1.97$ and a broad resonance signal at $g=4.65$. The spectrum at low field i.e., the EPR absorption at $g=4.65$ resonance can be attributed to isolated $\mathrm{Cr}^{3+}$ ions in rhombic symmetry subjected to strong crystal field effects $[27,28]$. The line shape of the EPR spectra of chromium ions in glasses is more complicated than in single crystals or polycrystalline substances. They are influenced by the absence of long-range order in glasses connected with various small distortions of the local environment of the ions from site to site. In addition to that, the symmetry axes of the ligand fields relative to the direction of the applied magnetic field are randomly oriented. Therefore the line shape is highly broadened [29]. The shape of ESR spectra at $g \sim 4.6$ it is reasonably some what Lorenzian in shape up to $5 \mathrm{~mol} \%$ of $\mathrm{Cr}_{2} \mathrm{O}_{7}$. Thereafter it is difficult to predict.

The other resonance at $g=1.97$ is generally observed and it has been attributed to the exchange coupled chromium ion pairs and is related to weakly distorted sites. In the present study, the resonance at $g=1.97$ is very narrow $(\Delta B \leq 10 \mathrm{mT})$ and we attribute this signal due to $\mathrm{Cr}^{5+}$ ions $[27,28,30-32]$. The

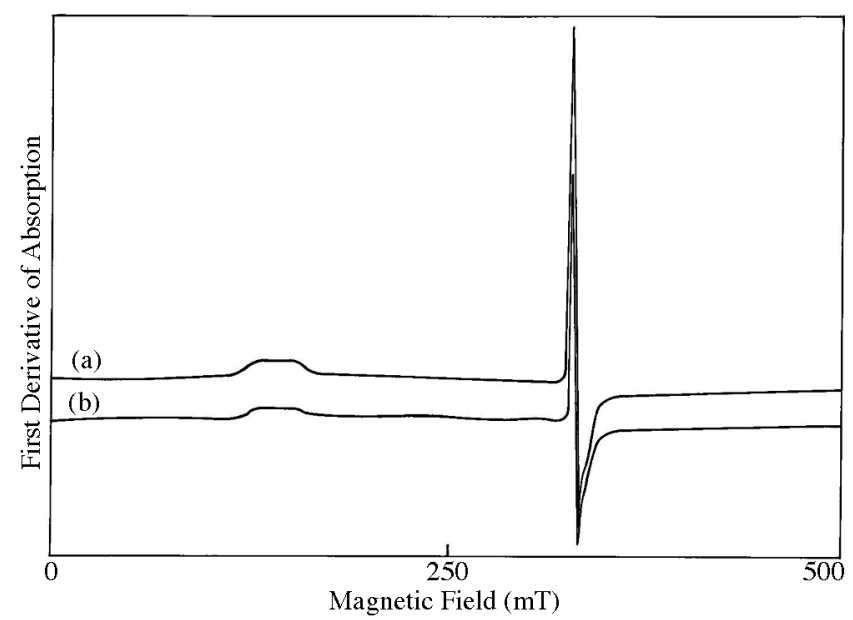

Fig. 1 Electron Paramagnetic Resonance spectra of (a) NaPbBTe: 8Cr and (b) KPbBTe:8Cr glass samples at room temperature. 


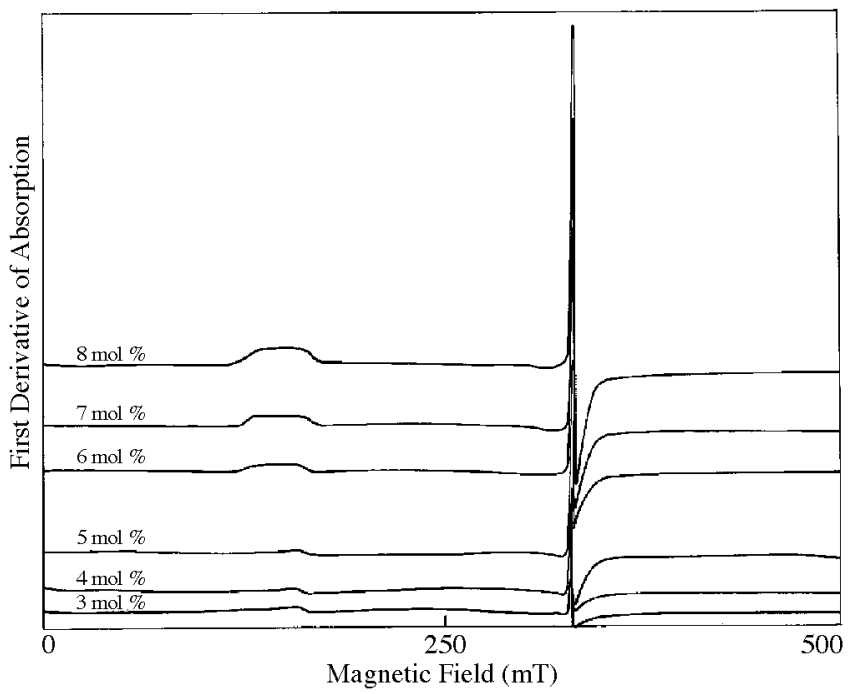

Fig. 2 Electron Paramagnetic Resonance spectra for various mol\% of $\mathrm{Cr}_{2} \mathrm{O}_{7}$ ions in $\mathrm{KPbBTe}: x \mathrm{Cr}(x=3$ to $8 \mathrm{~mol} \%$ ) glass samples at room temperature.

existence of $\mathrm{Cr}^{5+}$ ions might be due to in the process of melting the alkali lead borotellurite glass the $\mathrm{Cr}^{3+}$ is partly oxidized to $\mathrm{Cr}^{5+}$. The evidence for $\mathrm{Cr}^{5+}$ ions in glasses was already reported by Garif'yanov [30] through EPR spectroscopy. In case of $\mathrm{Cr}^{5+}$ ions in oxide glasses [27, 28, 30-32] a narrow and asymmetric resonance with $g \approx 1.98$ was evidenced. Asymmetry of EPR line shape for $\mathrm{Cr}^{5+}$ ions in these glasses is typical for centers with anisotropic $g$ values. The present investigations suggest that in alkali lead borotellurite glasses, $\mathrm{Cr}^{5+}$ ions exist which are responsible for the asymmetry line at $g=1.97$.

The EPR spectra of chromium ions in phosphate [33], fluorophosphates [33], borosulphates [34], fluoroberyllates [33], fluoroaluminates [35], fluorozirconates [36] and silicates [37] were reported by many authors. In all these glasses, two resonances have been observed at $g=5.0$ and $g=2.0$; these resonance signals have been attributed to isolated $\mathrm{Cr}^{3+}$ ions in strongly distorted sites and $\mathrm{Cr}^{3+}$ ion pairs [33-37] respectively. Ardelean et al. [27] studied the EPR spectra of $\mathrm{Cr}^{3+}$ ions in lead borate glasses. They observed two resonance signals at $g=5.1$ and $g=1.97$. The resonance signal at $g=5.1$ is typical for isolated $\mathrm{Cr}^{3+}$ ions sites of rhombic symmetry subjected to strong crystal field effects and the resonance signal at $g=1.97$ results from contributions from both $\mathrm{Cr}^{3+}$ and $\mathrm{Cr}^{5+}$ ions.

The EPR spectra for different mol\% $\mathrm{Cr}_{2} \mathrm{O}_{7}$ in KPbBTe: $x \mathrm{Cr}$ glasses (where $x=3,4,5,6,7$ and $8 \mathrm{~mol} \%$ ) are shown in Fig. 2. It is observed that the EPR spectrum exhibits marked concentration dependence.

\subsection{Calculation of number of spins $(N)$ participating in resonance}

The number of spins participating in a resonance can be calculated by comparing the area under the absorption curve with that of a standard $\left(\mathrm{CuSO}_{4} \cdot 5 \mathrm{H}_{2} \mathrm{O}\right.$ in this study) of known concentration. Weil et al. [38] gave the following expression which includes the experimental parameters of both sample and standard:

$$
N=\frac{A_{x}\left(\operatorname{scan}_{x}\right)^{2} G_{\text {std }}\left(B_{\mathrm{m}}\right)_{\mathrm{std}}\left(g_{\mathrm{std}}\right)^{2}[S(S+1)]_{\mathrm{std}}\left(P_{\mathrm{std}}\right)^{1 / 2}}{A_{\mathrm{std}}\left(\operatorname{scan}_{\mathrm{std}}\right)^{2} G_{x}\left(B_{\mathrm{m}}\right)_{x}\left(g_{x}\right)^{2}[S(S+1)]_{x}\left(P_{x}\right)^{1 / 2}}[\mathrm{std}],
$$

where $A$ is the area under the absorption curve which can be obtained by double integrating the first derivative EPR absorption curve, "scan" is the magnetic field corresponding to unit length of the chart, $G$ 


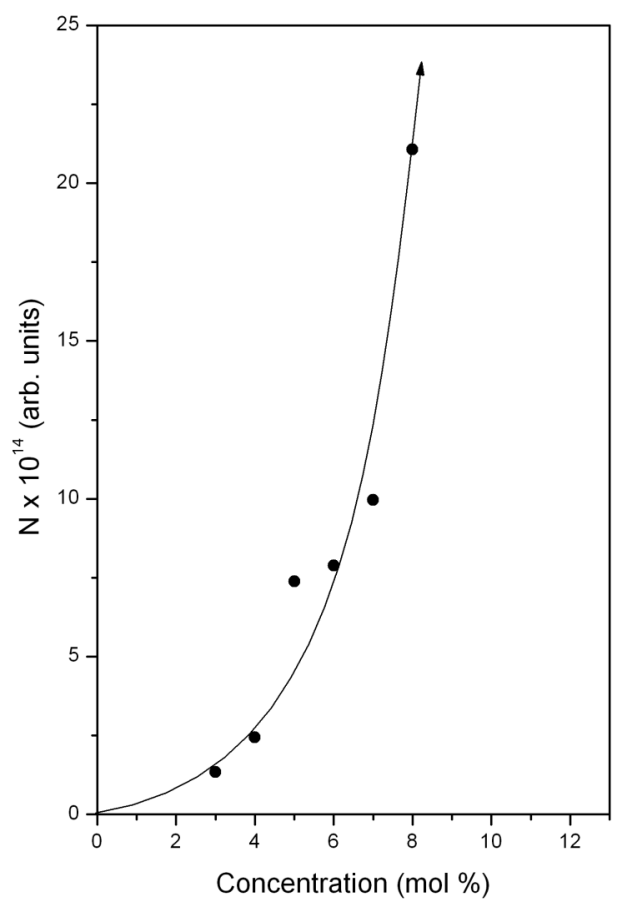

Fig. 3 Variation of number of spins against different $\mathrm{mol}_{0} \quad \mathrm{Cr}_{2} \mathrm{O}_{7}$ ions in $\mathrm{KPbBTe}$ glass system.

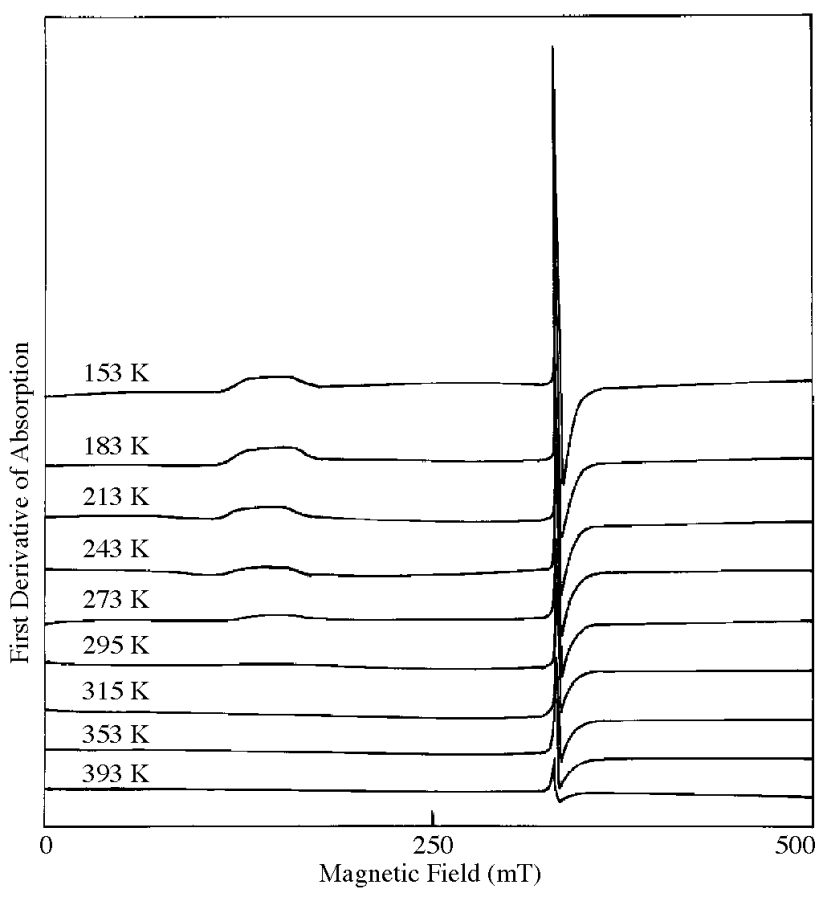

Fig. 4 Electron Paramagnetic Resonance spectra of KPbBTe: $8 \mathrm{Cr}$ glass sample at different temperatures.

is the gain, $B_{\mathrm{m}}$ is the modulation field width, $g$ is the $g$-factor, $S$ is the spin of the system in its ground state, and $P$ is the power of the microwave. The subscripts ' $x$ ' and 'std' represent the corresponding quantities for $\mathrm{Cu}^{2+}$ glass sample and the reference $\left(\mathrm{CuSO}_{4} \cdot 5 \mathrm{H}_{2} \mathrm{O}\right)$ respectively. Figure 3 shows a plot of number of spins participating in resonance as a function of $\mathrm{Cr}_{2} \mathrm{O}_{7}$ content. The number of spins increases with the concentration of chromium as shown in Table 2. The EPR spectra of $8 \mathrm{~mol}_{0} \mathrm{Cr}_{2} \mathrm{O}_{7}$ doped in potassium lead borotellurite $(\mathrm{KPbBTe}: 8 \mathrm{Cr}$ ) glass sample have been recorded at different temperatures $(153-393 \mathrm{~K})$ and are shown in Fig. 4. The temperature dependence of the intensity of the resonance line at $g=1.97$ for KPbBTe: $8 \mathrm{Cr}$ glass sample has been calculated by using the above Eq. (1) and is shown in Fig. 5 which indicates that as the temperature is lowered the number of spins increases and a linear relationship between $\log N$ and $1 / T$ is observed. This is the phenomenon that can be expected from the Boltzmann law. The slope of the graph will give activation energy. The activation energy thus calculated is found to be $31.69 \times 10^{-22} \mathrm{~J}(0.019 \mathrm{eV})$.

Table 2 Number of spins $(N)$, theoretical values of optical basicity $\left(\Lambda_{\mathrm{th}}\right)$, optical band gap $\left(E_{\mathrm{opt}}\right)$ and $\operatorname{Ur}$ bach $(\Delta E)$ energies for the glass samples studied in the present work.

\begin{tabular}{lllll}
\hline glass sample & $\begin{array}{l}\text { number of spins per kg } \\
\left(10^{14} \text { arb. units }\right)\end{array}$ & $\begin{array}{l}\text { optical basicity } \\
\Lambda_{\text {th }}\end{array}$ & $\begin{array}{l}\text { optical band gap energy } \\
E_{\text {opt }}(\mathrm{eV})\end{array}$ & $\begin{array}{l}\text { Urbach energy } \\
\Delta E(\mathrm{eV})\end{array}$ \\
\hline KPbBTe:3Cr & 1.34 & 0.5448 & 2.52 & 0.10 \\
KPbBTe:4Cr & 2.44 & 0.5415 & 2.42 & 0.12 \\
KPbBTe:5Cr & 7.38 & 0.5328 & 2.37 & 0.22 \\
KPbBTe:6Cr & 7.89 & 0.5349 & 2.28 & 0.25 \\
KPbBTe:7Cr & 9.95 & 0.5316 & 2.22 & 0.27 \\
KPbBTe:8Cr & 21.06 & 0.5283 & 2.12 & 0.30 \\
\hline
\end{tabular}




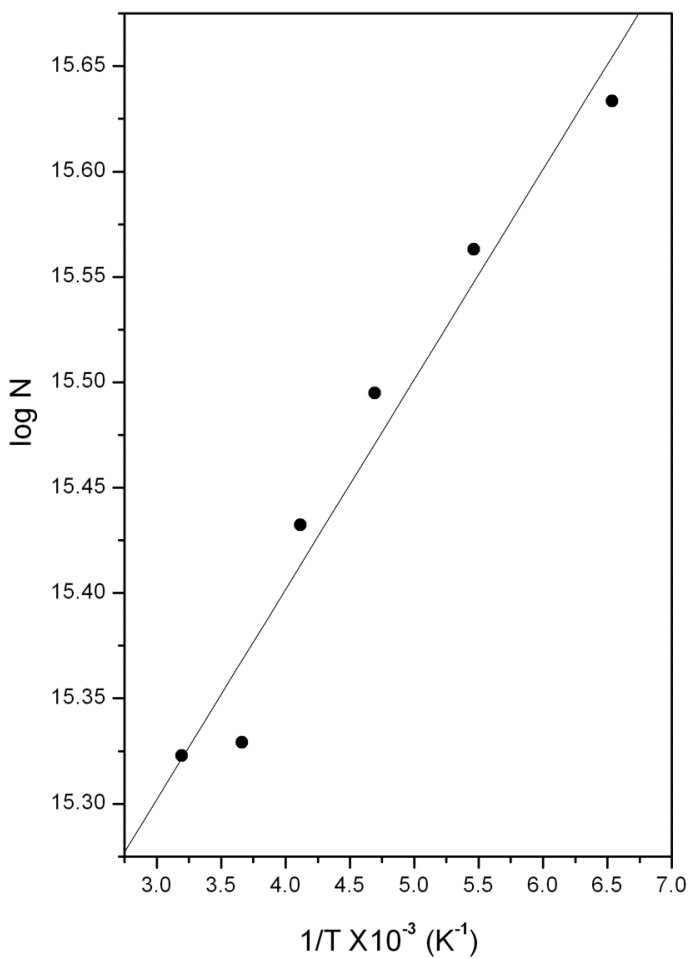

Fig. 5 A plot of $\log N$ against $1 / T$ for KPbBTe $: 8 \mathrm{Cr}$ glass sample.

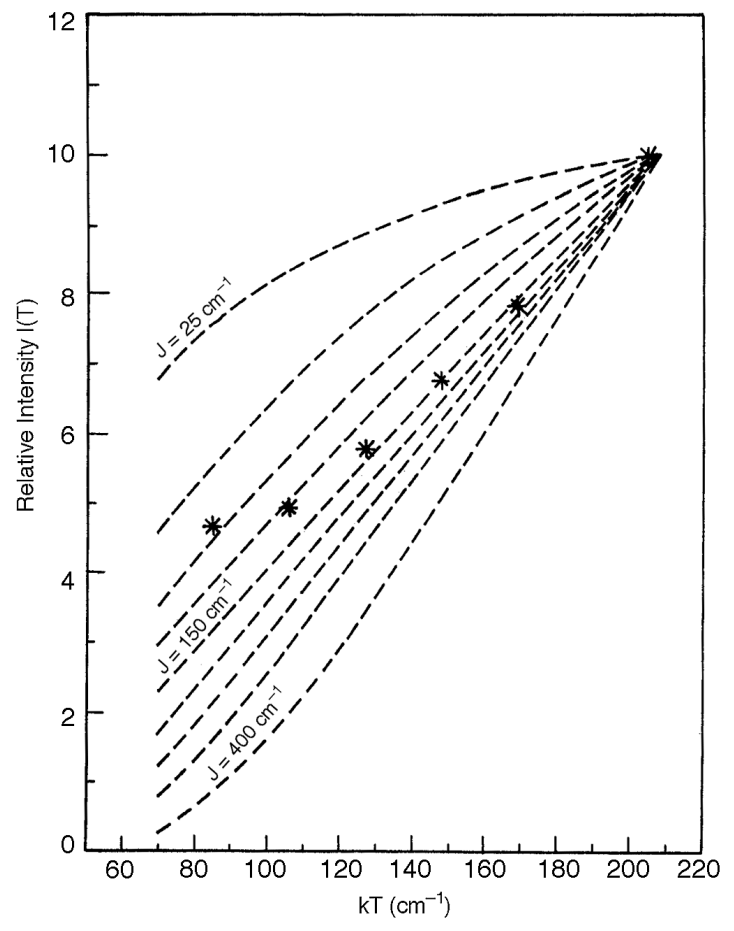

Fig. 6 Variation of relative intensity of EPR spectra with $k T$ for various $J$ values. (The stars indicate the experimental relative intensities which are superimposed with the theoretical curves).

\subsection{Coupling constant ' $J$ ' between chromium ion pairs}

Fournier et al. [39] gave the following expression to calculate the relative intensity at various temperatures.

$$
I(t)=\frac{4 \exp \left(\frac{-J}{k T}\right)+20 \exp \left(\frac{-3 J}{k T}\right)+56 \exp \left(\frac{-6 J}{k T}\right)}{1+3 \exp \left(\frac{-J}{k T}\right)+5 \exp \left(\frac{-3 J}{k T}\right)+7 \exp \left(\frac{-6 J}{k T}\right)},
$$

where $J$ is the exchange coupling constant between $\mathrm{Cr}^{3+}$ ion pairs, $k$ is the Boltzmann constant and $T$ is the absolute temperature. The intensities were determined by double integrating the EPR first derivative signal and the relative intensities were measured with respect to the intensity at room temperature. Figure 6 shows a plot of relative intensity $I(T)$ versus $k T$ for different $J$ values. Figure 6 also shows the experimental relative intensities superimposed on theoretical curves. Fournier et al. [39] has taken a spin $\frac{1}{2}$ sample as a standard for measuring the relative intensities. In the present work, the relative intensities were measured with respect to the intensity at room temperature. Hence, all the curves have been scaled to a factor of 10 at room temperature (corresponding to $k T=209 \mathrm{~cm}^{-1}$ ). The experimental data is close to the theoretical curves at $J=150 \mathrm{~cm}^{-1}$. This value is higher than the value reported $\left(J=24 \pm 2 \mathrm{~cm}^{-1}\right)$ by Fournier et al. [39] but is in the same order for chromium ions in ruby reported in literature [40, 41].

\section{Optical absorption studies}

The optical absorption spectrum for $8 \mathrm{~mol} \% \mathrm{Cr}_{2} \mathrm{O}_{7}$ in potassium lead borotellurite glass sample in the wavelength region 200-900 nm is shown in Fig. 7. The analysis of EPR spectra of glass samples indi- 


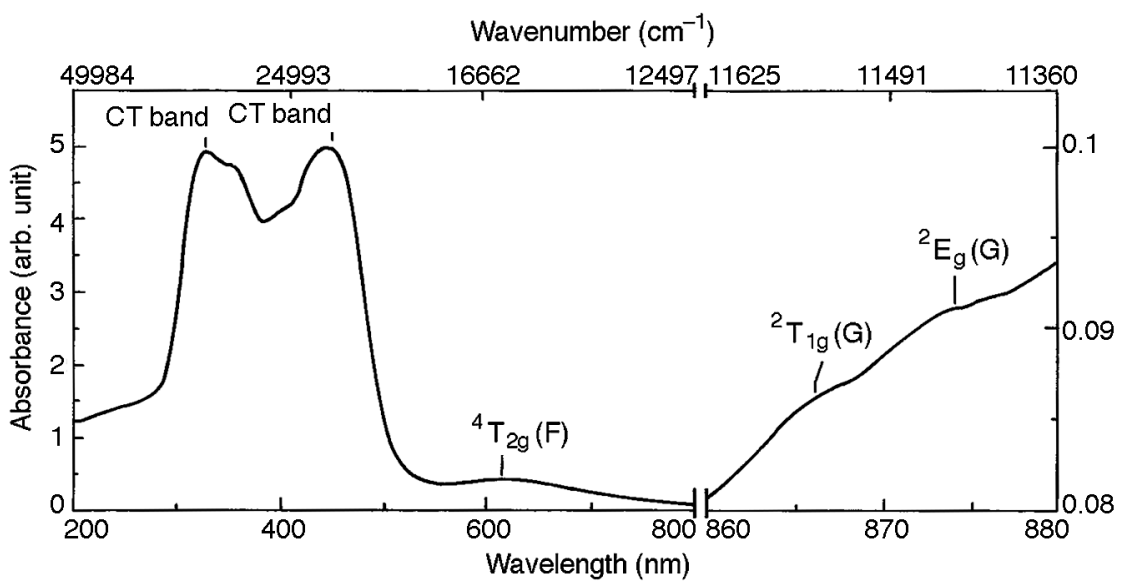

Fig. 7 Optical absorption spectrum of $\mathrm{KPbBTe}: 8 \mathrm{Cr}$ glass sample at room temperature.

cates the presence of both $\mathrm{Cr}^{3+}$ and $\mathrm{Cr}^{5+}$ ions. $\mathrm{Cr}^{3+}$ ions belong to $\mathrm{d}^{3}$ configuration and have large octahedral site preference energy (OSPE) [42]. The ground state is always ${ }^{4} A_{2 \mathrm{~g}}(F)$ irrespective of the strength of the crystal field. In general, the $\mathrm{Cr}^{3+}$ ions in an octahedral symmetry are characterized by three spinallowed transitions ${ }^{4} A_{2 \mathrm{~g}}(F) \rightarrow{ }^{4} T_{2 \mathrm{~g}}(F),{ }^{4} A_{2 \mathrm{~g}}(F) \rightarrow{ }^{4} T_{1 \mathrm{~g}}(F)$ and ${ }^{4} A_{2 \mathrm{~g}}(F) \rightarrow{ }^{4} T_{1 \mathrm{~g}}(P)$. In case of $\mathrm{Cr}^{5+}$ ions (belong to $\mathrm{d}^{1}$ configuration) the optical transitions are generally characterized by two spin allowed transitions [43], corresponding to ${ }^{2} B_{2 \mathrm{~g}} \rightarrow{ }^{2} E_{\mathrm{g}}$ at around $13700 \mathrm{~cm}^{-1}$, and ${ }^{2} B_{2 \mathrm{~g}} \rightarrow{ }^{2} B_{1 \mathrm{~g}}$ around $18000-23500 \mathrm{~cm}^{-1}$. In the present study (Fig. 7), the authors observed an intense band at $444 \mathrm{~nm}\left(22490 \mathrm{~cm}^{-1}\right)$ and a broad band at $635 \mathrm{~nm}\left(15740 \mathrm{~cm}^{-1}\right)$. The broad band at $15740 \mathrm{~cm}^{-1}$ has been assigned to ${ }^{4} A_{2 \mathrm{~g}}(F) \rightarrow{ }^{4} T_{2 \mathrm{~g}}(F)$ transition. The two weak bands centered at $866 \mathrm{~nm}\left(11545 \mathrm{~cm}^{-1}\right)$ and $874 \mathrm{~nm}\left(11440 \mathrm{~cm}^{-1}\right)$ have been assigned to the transitions ${ }^{4} A_{2 \mathrm{~g}}(F) \rightarrow{ }^{2} T_{1 \mathrm{~g}}(G)$ and ${ }^{4} A_{2 \mathrm{~g}}(F) \rightarrow{ }^{2} E_{\mathrm{g}}(G)$ respectively. The bands observed at visible and near infra-red regions are characteristic of $\mathrm{Cr}^{3+}$ ions. In the present study we did not observe the bands corresponding to $\mathrm{Cr}^{5+}$ ions in the optical absorption spectrum might be due to $\mathrm{Cr}^{3+}$ is partly oxidized to $\mathrm{Cr}^{5+}$ ions during melting the glass and the $\mathrm{Cr}^{5+}$ ions involved is small. The crystal field parameter $\mathrm{Dq}$ is evaluated from the band position of ${ }^{4} A_{2 \mathrm{~g}}(F) \rightarrow{ }^{4} T_{2 \mathrm{~g}}(F)$ and found to be $1574 \mathrm{~cm}^{-1}$. This value is in the expected order for $\mathrm{Cr}^{3+}$ ions in octahedral symmetry [43]. The other bands at $444 \mathrm{~nm}\left(22490 \mathrm{~cm}^{-1}\right)$, $400 \mathrm{~nm}\left(24990 \mathrm{~cm}^{-1}\right)$ and $354 \mathrm{~nm}\left(28280 \mathrm{~cm}^{-1}\right)$ have been assigned to charge transfer bands.

\subsection{Theoretical optical basicity $\left(\Lambda_{\mathrm{th}}\right)$}

The optical basicity of an oxide glass will reflect the ability of the glass to donate negative charge to the probe ion [44]. Duffy and Ingram [45] proposed that the optical basicity can be predicted from the composition of the glass and basicity moderating parameters of various cations present.

The theoretical values of the optical basicity $\Lambda_{\mathrm{th}}$ of the glasses can be calculated using the formula [45]

$$
\Lambda_{\mathrm{th}}=\sum_{i=1}^{n} \frac{Z_{i} r_{i}}{2 \gamma_{i}},
$$

where $n$ is the total number of cations present, $Z_{i}$ is the oxidation number of the $i^{\text {th }}$ cation, $r_{i}$ is the ratio of number of $i^{\text {th }}$ cations to the number of oxides present and $\gamma_{i}$ is the basicity moderating parameter of the $i^{\text {th }}$ cation. The basicity moderating parameter $\gamma_{i}$ can be calculated [45] from the following equation:

$$
\gamma_{i}=1.36\left(x_{i}-0.26\right),
$$

where $x_{i}$ is the Pauling electronegativity [46] of the cation. The theoretical values of optical basicities have been calculated for all the glass samples and are presented in Table 2. From the Table, it is seen that 


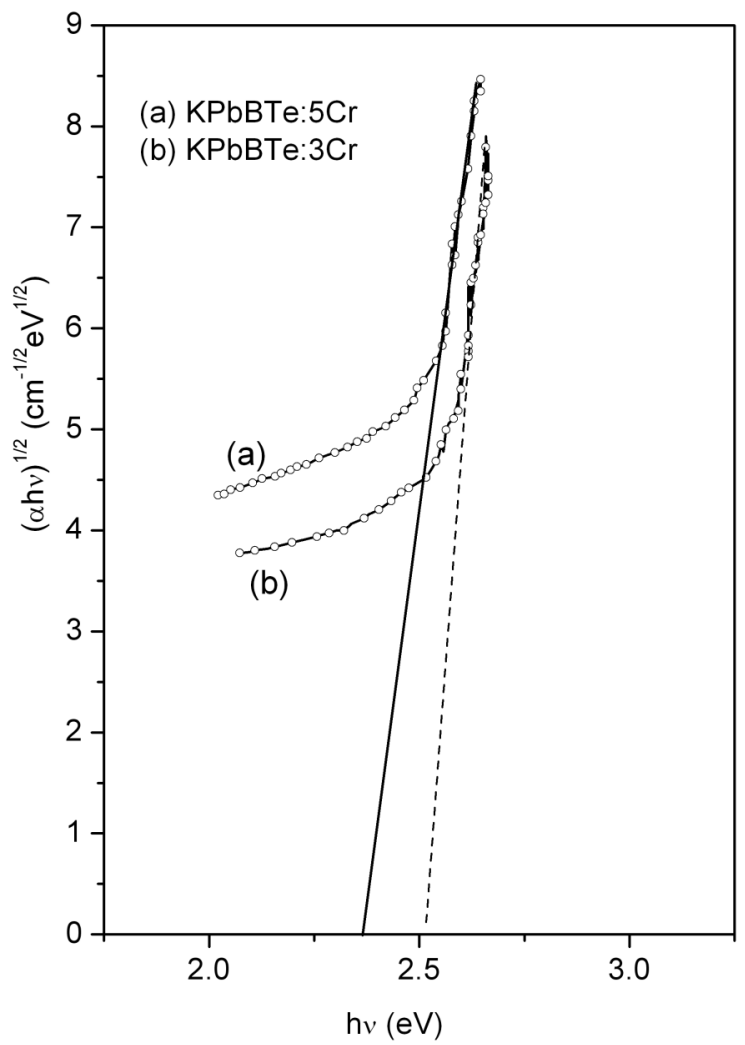

Fig. 8 Plots between $(\alpha h v)^{1 / 2}$ versus $h v$ for $\mathrm{KPbBTe}: 3 \mathrm{Cr}$ and $\mathrm{KPbBTe}: 5 \mathrm{Cr}$ glass samples.

the optical basicity is decreasing with the increasing concentration of chromium. Hence it is observed that the covalency between chromium and oxygen ions should increase with the increase of concentration of chromium content.

\subsection{Optical band gap $\left(E_{\text {opt }}\right)$ and Urbach energies $(\Delta E)$}

The optical band gap and Urbach energies of all the glass samples have been obtained from their ultraviolet absorption edges. The optical band gap energy in the amorphous system is closely related to the energy gap between valence and conduction bands [47]. In glasses, the glass forming anions influences the conduction band, the cations play an indirect but significant role [47]. The Urbach energy gives the width of the tails of localized states within the optical band gap. At the absorption edge, random internal electric fields will dominate the broadening of the exciton levels due to the lack of long range order or presence of defects $[47,48]$. The least $\Delta E$ i.e., sharp absorption edge suggests that the defects are minimum facilitating long-range order. The main feature of the absorption edge of amorphous semiconductors, particularly at the lower values of absorption coefficient is an exponential increase of the absorption coefficient $\alpha(v)$ with photon energy in accordance with an empirical relation [49]

$$
\alpha=\alpha_{0} \exp \left(\frac{h v}{\Delta E}\right)
$$

where $\alpha_{0}$ is a constant, $\Delta E$ is the Urbach energy and $v$ is the frequency of radiation.

The absorption coefficient $\alpha(v)$ can be determined near the edge using the formula

$$
\alpha(v)=\ln \left(\frac{I_{0}}{I}\right)=2.303 \mathrm{~A} / \mathrm{d}
$$




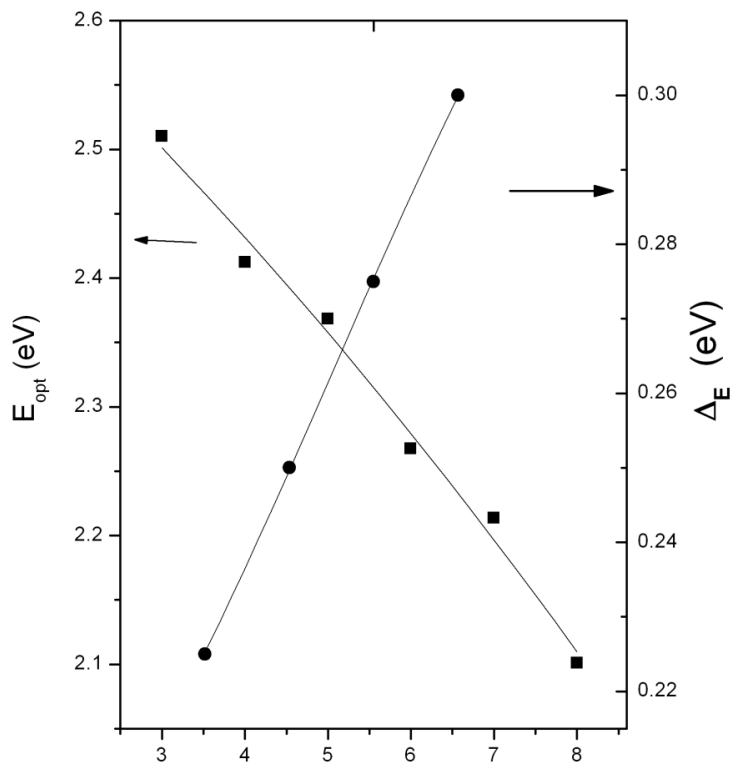

Fig. 9 A plot of optical band gap $\left(E_{\text {opt }}\right)$ and Urbach $(\Delta E)$ energies versus concentration of chromium (in $\mathrm{mol} \%$ ) in $\mathrm{KPbBTe}$ glass samples.

where $A$ is the absorbance at frequency $v$ and $d$ is the thickness of the glass sample. For an absorption by indirect transitions, the equation takes the form

$$
E_{\mathrm{opt}}=h v-\left(\frac{\alpha h v}{B}\right)^{1 / 2}
$$

where ' $B$ ' is a constant and $E_{\mathrm{opt}}$ is the optical band gap energy. This relation has been applied to many oxide glasses [22]. Figure 8 shows the plots between $(\alpha h v)^{1 / 2}$ versus $h v$ for $\mathrm{KPbBTe}: 3 \mathrm{Cr}$ and $\mathrm{KPbBTe}: 5 \mathrm{Cr}$ glass samples respectively. The optical band gap energy is obtained by extrapolating the linear region of the curve to the $h v$ axis. The values of the optical band gap and Urbach energies calculated in the present work for different glass samples are listed in Table 2. The addition of chromium to the glass samples causes a reduction in the optical band gap and this is consistent with the initiation of band tailing suppressed to occur at lower values of $N(E)$, the density of states function, as reported by Hogarth and Novikov [50]. The optical band gap energies obtained in the present work is of the same order as reported in literature for copper tellurium oxide and tellurium borate glasses [21, 51].

Plots have been drawn between $\ln \alpha$ and $h v$ for $\mathrm{KPbBTe}: 3 \mathrm{Cr}$ and $\mathrm{KPbBTe}: 5 \mathrm{Cr}$ glass samples (not shown here) and the reciprocal of slope of the linear portion of $\ln \alpha$ versus $h v$ graph will give Urbach energy. Figure 9 shows a plot of optical band gap energy and Urbach energy as a function of chromium ion content in the glass. From the figure it is observed that the band gap energy decreases whereas Urbach energy increases with increasing chromium content. The increasing chromium content may cause the localized states of the colour centers to overlap and extend in the mobility gap. This overlap may give us evidence for decreasing $E_{\mathrm{opt}}$ when chromium content is increased in the glass matrix.

From the Table 2 it can be observed that the least Urbach energy $(0.10 \mathrm{eV})$ is observed for $\mathrm{KPbBTe}: 3 \mathrm{Cr}$ glass sample. This suggests that the defects are minimum in this glass sample. The increase in Urbach energy with chromium content can be considered due to increased defects.

\section{Conclusions}

In alkali lead borotellurite glasses, the EPR spectra of chromium ions exhibit two resonance signals at $g=4.65$ and $g=1.97$. The EPR absorption at $g=4.65$ resonance can be attributed to isolated $\mathrm{Cr}^{3+}$ ions in rhombic symmetry subjected to strong crystal field effects and the resonance at $g=1.97$ is very narrow ( $\Delta B \leq 10 \mathrm{mT})$, we attribute this signal is due to $\mathrm{Cr}^{5+}$ ions. The number of spins $(N)$ participating in reso- 
nance exhibit a linear relationship between $\log N$ and $1 / T$ obeying the Boltmann distribution law. The relative intensities of EPR signals have been measured at various temperatures to evaluate the exchange coupling constant $J$. The experimental relative intensities are close to the calculated relative intensities at $J=150 \mathrm{~cm}^{-1}$. The optical absorption spectrum shows bands characteristic of $\mathrm{Cr}^{3+}$ ions in an octahedral symmetry. The optical band gap $E_{\text {opt }}$ and Urbach energies $\Delta E$ were evaluated from their ultraviolet absorption edges. The optical band gap energy $E_{\mathrm{opt}}$ and Urbach energy $\Delta E$ are found to be dependent upon dopant concentration.

Acknowledgements Dr. R. P. S. Chakradhar is grateful to the Science and Engineering Research Council SERC, (Department of Science and Technology, DST) New Delhi, for the award of Fast Track research project under Young scientist scheme.

\section{References}

[1] F. Rasheed, K. P. O’Donnell, B. Henderson, and D. B. Hillis, J. Phys.: Condens. Matter 3, 3825 (1991).

[2] H. Burger, K. Kneipp, H. Hobert, W. Vogel, V. Kozhukharov, and S. Neov, J. Non-Cryst. Solids 151, 134 (1992).

[3] A. Majchrowski, in: Solid State Crystals: Materials Science and Applications, edited by J. Zmija, A. Rogalski, and J. Zielinski, Proc. SPIE 2373, 98 (1995).

[4] S. Karamazov, J. Navratil, J. Horak, D. Lezal, J. Bludska, and J. Pedlikova, Phys. Chem. Glasses 43, 224 (2002).

[5] P. Armand and P. Charton, Phys. Chem. Glasses 43, 291 (2002).

[6] F. Rasheed, K. P. O’Donnel, B. Henderson, and D. B. Hollis, J. Phys.: Condens. Matter 3, 1915 (1991).

[7] M. Casalboni, V. Ciafardone, G. Giuli, B. Izzi, E. Paris, and P. Prosphosito, J. Phys.: Condens. Matter 8, 9059 (1996).

[8] R. Jabloski, M. Palczewskaand, and A. Pajaczkowska, J. Magn. Magn. Mater. 167, 99 (1997).

[9] M. G. Zhao and Y. Lei, J. Phys.: Condens. Matter 9, 529 (1997).

[10] I. Ardelean, M. Peteanu, V. Simon, C. Bob, and S. Fillip, J. Mater. Sci. 33, 357 (1998).

[11] I. Ardelean, M. Peteanu, V. Ioncu, and N. Muresan, Mod. Phys. Lett. B 15, 941 (2001).

[12] I. Ardelean and S. Fillip, J. Optoelectron. Adv. Mater. 5, 157 (2003).

[13] H. L. Smith and A. J. Cohen, Phys. Chem. Glasses 4, 173 (1963).

[14] P. C. Schultz, J. Am. Ceram. Soc. 57, 307 (1974).

[15] E. Baiocchi, A. Montenero, and M. Bettinelli, J. Non-Cryst. Solids 46, 203 (1981).

[16] R. H. Clarke, L. J. Andrews, and H. A. Frank, Chem. Phys. Lett. 85, 161 (1982).

[17] A. Van Die, A. C. H. I. Leenaers, G. Blasse, and W. F. Vander Weg, J. Non-Cryst. Solids 99, 32 (1988).

[18] J. Lakshmana Rao, B. Sreedhar, M. Ramachandra Reddy, and S. V. J. Lakshman, J. Non-Cryst. Solids 111, 228 (1989).

[19] M. Peteanu, V. Simon, N. Muresan, I. Ardelean, and S. Filip, J. Mater. Sci. Technol. 13, 374 (1997).

[20] R. Jablonski, M. Palczewska, and A. Pajaczkowska, J. Magn. Magn. Mater. 167, 529 (1997).

[21] R. P. Sreekanth Chakradhar, A. Murali, and J. Lakshmana Rao, J. Alloys Compd. 281, 99 (1998).

[22] R. Rama Kumar and B. C. Venkata Reddy, Radiat. Eff. Defects Solids 147, 293 (1999).

[23] M. Haouari, M. Ajroud, H. Ben Ouada, H. Maaref, A. Brenier, and C. Garapon, phys. stat. sol. (b) 215, 1165 (1999).

[24] V. S. Costa, F. S. Lameivas, and M. V. B. Pinheiro, J. Non-Cryst. Solids 273, 209 (2000).

[25] I. Ardelean, M. Peteanu, S. Simon, S. Filip, V. Simon, C. Bob, and N. Muresan, Roman. Rep. Phys. 51, 505 (2000).

[26] I. Ardelean, M. Peteanu, V. Ioncu, and N. Muresan, Mod. Phys. Lett. B 15, 941 (2001).

[27] I. Ardelean, Gh. Iionca, M. Peteanu, E. Barbos, and E. Indrea, J. Mater. Sci. 17, 1988 (1982).

[28] R. J. Landry, J. T. Fournier, and C. G. Young, J. Chem. Phys. 46, 1285 (1967).

[29] R. Bruckner, M. Sammet, and H. Stockhorst, J. Non-Cryst. Solids 49, 273 (1980).

[30] J. Wong and C. A. Angell, Appl. Spectrosc. Rev. 4, 155 (1971).

[31] N. S. Garif'yanov, Sov. Phys. Solid State 4, 1795 (1963).

[32] R. Bruckner, N. Sammet, and H. Stockhorst, J. Non-Cryst. Solids 40, 273 (1980).

[33] Gan Fuxi, Deng He, and Liu Huiming, J. Non-Cryst. Solids 52, 135 (1982).

[34] A. Srinivasa Rao, J. Lakshmana Rao, and S. V. J. Lakshman, Solid State Commun. 85, 529 (1993). 
[35] J. M. Dance, J. J. Videau, and J. Portier, J. Non-Cryst. Solids 86, 88 (1986).

[36] E. A. Harris, Phys. Chem. Glasses 28, 196 (1987).

[37] M. Casalboni, V. Ciafardone, G. Giuli, B. Izzi, E. Paris, and P. Prosphosito, J. Phys.: Condens. Matter 8, 9059 (1996).

[38] J. A. Weil, J. R. Bolton, and J. E. Wertz, Electron Paramagnetic Resonance - Elementary Theory and Practical Applications (Wiley, New York, 1994), p. 498.

[39] J. T. Fournier, R. J. Landry, and R. H. Bartram, J. Chem. Phys. 55, 2522 (1971).

[40] H. Statz, L. Rimai, M. J. Weber, G. A. de Mars, and G. F. Koster, J. Appl. Phys. 32, 2185 (1961).

[41] L. F. Mollenauer and A. L. Schawlow, Phys. Rev. 168, 309 (1968).

[42] J. Wong and C. A. Angell, Glass: Structure by Spectroscopy (Marcel Dekker, New York, 1976), p. 225.

[43] A. B. P. Lever, Inorganic Electronic Spectroscopy (Elsevier, Amsterdam, 1968), p. 265.

[44] A. J. Easteal and A. T. Marcom, J. Non-Cryst. Solids 34, 29 (1979).

[45] J. A. Duffy and M. D. Ingram, J. Inorg. Nucl. Chem. 37, 1203 (1975)

[46] L. Pauling, The Nature of Chemical Bond, 3rd edition (Cornell University Press, New York, 1960), p. 93.

[47] G. Fuxi, Optical and Spectroscopic Properties of Glasses (Springer, Berlin, 1992), p. 62.

[48] E. A. Davis and N. F. Mott, Philos. Mag. 22, 903 (1970).

[49] M. A. Hassan and C. A. Hogarth, J. Mater. Sci. 23, 2500 (1988).

[50] C. A. Hogarth and A. A. Novikov, J. Phys. D: Appl. Phys. 16, 675 (1983).

[51] A. I. Sabry and M. M. El-Samanoudy, J. Mater. Sci. 30, 3930 (1995). 